\title{
Sofas and Infant Mortality
}

AUTHORS: Lauren R. Rechtman, MD, a Jeffrey D. Colvin, MD, JD, b,c Peter S. Blair, PhD, ${ }^{d}$ and Rachel Y. Moon, MD ${ }^{a, e}$

aDepartment of Pediatrics, George Washington University School of Medicine and Health Sciences, Washington, District of Columbia; ${ }^{b}$ Department of Pediatrics, Children's Mercy Hospitals and Clinics, Kansas City, Missouri; 'Department of Pediatrics, University of Missouri-Kansas City School of Medicine, Kansas City, Missouri; dUniversity of Bristol, Bristol, United Kingdom; and ${ }^{e}$ Goldberg Center for Community Pediatric Health, Children's National Health System, Washington, District of Columbia

KEY WORDS

SIDS, suffocation, injury, sofa

ABBREVIATIONS

aOR - adjusted odds ratio

ASSB - accidental suffocation and strangulation in bed CDR-CRS—Child Death Review and Case Reporting System $\mathrm{Cl}$-confidence interval

SIDS—-sudden infant death syndrome

Dr Rechtman carried out the initial analyses and drafted the initial manuscript; Dr Colvin conducted data analysis and reviewed and revised the manuscript; Drs Blair and Moon contributed to the conception and design, contributed to the interpretation of data, and reviewed and revised the manuscript; and all authors approved the final manuscript as submitted.

www.pediatrics.org/cgi/doi/10.1542/peds.2014-1543

doi:10.1542/peds.2014-1543

Accepted for publication Aug 20, 2014

Address correspondence to Rachel Y. Moon, MD, Goldberg Center for Community Pediatric Health, Children's National Health System, 111 Michigan Ave NW, Washington, DC 20010. E-mail: rmoon@cnmc.org

PEDIATRICS (ISSN Numbers: Print, 0031-4005; Online, 1098-4275).

Copyright (C) 2014 by the American Academy of Pediatrics

FINANCIAL DISCLOSURE: The authors have indicated they have no financial relationships relevant to this article to disclose.

FUNDING: Authors received support from the National Institutes of Health (grant P20MD000198) and the Maternal and Child Health Branch, Health Resources and Services Administration (grant R40MC21511). The funding was used for design and conduct of the study; collection, management, analysis, and interpretation of the data and manuscript preparation. The study sponsor had no role in study design, collection, analysis, and interpretation of data, writing of the manuscript, or the decision to submit the manuscript for publication. Dr Rechtman wrote the first draft of the manuscript; no honorarium, grant, or other form of payment was given to anyone to produce the manuscript. Funded by the National Institutes of Health (NIH).

POTENTIAL CONFLICT OF INTEREST: The authors have indicated they have no potential conflicts of interest to disclose.
WHAT'S KNOWN ON THIS SUBJECT: Sleeping on a sofa increases the risk of sudden and unexpected infant death.

WHAT THIS STUDY ADDS: Infant deaths on sofas are associated with nonsupine placement, being found in side position, surface sharing, changing sleep location, and experiencing prenatal tobacco exposure. These results may help explain why sofa sleeping is hazardous for infants.
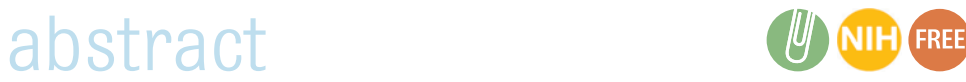

OBJECTIVE: Sleeping on sofas increases the risk of sudden infant death syndrome and other sleep-related deaths. We sought to describe factors associated with infant deaths on sofas.

METHODS: We analyzed data for infant deaths on sofas from 24 states in 2004 to 2012 in the National Center for the Review and Prevention of Child Deaths Case Reporting System database. Demographic and environmental data for deaths on sofas were compared with data for sleep-related infant deaths in other locations, using bivariate and multivariable, multinomial logistic regression analyses.

RESULTS: A total of 1024 deaths on sofas made up $12.9 \%$ of sleeprelated infant deaths. They were more likely than deaths in other locations to be classified as accidental suffocation or strangulation (adjusted odds ratio [aOR] 1.9; 95\% confidence interval [CI], 1.6-2.3) or ill-defined cause of death (a0R 1.2; 95\% Cl, 1.0-1.5). Infants who died on sofas were less likely to be Hispanic (aOR 0.7; 95\% Cl, 0.6-0.9) compared with non-Hispanic white infants or to have objects in the environment (aOR 0.6; 95\% $\mathrm{Cl}, 0.5-0.7)$ and more likely to be sharing the surface with another person (a0R $2.4 ; 95 \% \mathrm{Cl}, 1.9-3.0$ ), to be found on the side (a0R 1.9; $95 \% \mathrm{Cl}, 1.4-2.4)$, to be found in a new sleep location (aOR 6.5; 95\% Cl, 5.2-8.2), and to have had prenatal smoke exposure (a0R 1.4; 95\% Cl, 1.2-1.6). Data on recent parental alcohol and drug consumption were not available.

CONCLUSIONS: The sofa is an extremely hazardous sleep surface for infants. Deaths on sofas are associated with surface sharing, being found on the side, changing sleep location, and experiencing prenatal tobacco exposure, which are all risk factors for sudden infant death syndrome and sleep-related deaths. Pediatrics 2014;134:e1293-e1300 
Sudden infant death syndrome (SIDS) is the leading cause of infant mortality after the first 30 days of life in the United States, with a rate of 53.9 deaths per 100000 live births. ${ }^{1}$ The incidence of SIDS has declined $>50 \%$ since $1992,1,2,3$ when the national "Back to Sleep" campaign was launched after research demonstrated the association between SIDS and prone sleep position. ${ }^{4}$ However, during this time the rates of other sleep-related infant deaths (eg, accidental suffocation, strangulation, ill-defined causes) have

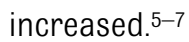

The risk of SIDS and other sleep-related infant deaths can be affected by an infant's sleep environment. Soft bedding, ${ }^{8}$ sleeping somewhere other than in a crib (eg, on a sofa), ${ }^{9}$ surface sharing (when an infant is sleeping on the same surface as another person), ${ }^{10}$ and bumper pads ${ }^{11}$ contribute to an unsafe sleep environment. In 2011, the American Academy of Pediatrics released expanded recommendations for a safe sleep environment to reduce the risk of all sleep-related infant deaths. ${ }^{12}$ However, many infants continue to be placed in unsafe sleep environments. ${ }^{13,14}$

Sleeping on sofas is extremely hazardous. Compared with sleeping on other surfaces (eg, beds, cribs), it increases the risk 49- to 67-fold. 8,9,15-17 However, less is known about the specific factors associated with infant deaths on sofas. One study has described the dangers associated with sofa sleeping but included only 10 sofa deaths. ${ }^{18}$ The purpose of this study is to describe the environmental and situational factors associated with infant deaths on sofas, as compared with other sleep-related infant deaths.

\section{METHODS}

\section{Data Source}

Data were obtained from the National Center for the Review and Prevention of Child Deaths Child Death Review and
Case Reporting System (CDR-CRS) database. The CDR-CRS, funded by the Maternal and Child Health Bureau, is a web-based system used for the collection, reporting, and analysis of individual child deaths by state child death review teams. ${ }^{19,20}$ The database includes $>84100$ child deaths, including $>45300$ infant deaths. ${ }^{19}$ As of June 2014, 35 states were contributing to the database, which contains $>1700$ data elements, with each element linked to definitions and a code book to ensure standardization and consistency in reporting. ${ }^{19}$ (At the time these data were collected, 24 states were participating.) Data were analyzed from all states that made their data available for the relevant years. Data sources include death scene investigations, autopsies, law enforcement reports, medical records, and death certificates. The reporting system includes information on the child, family, and supervisor at the time of death, as well as data about incident characteristics, investigation actions, risk and protective factors, and services needed or provided. ${ }^{19}$

\section{Subjects}

The study population included all infants ( $\leq 365$ days of age) whose death was recorded in the CDR-CRS as a sleep-related death (ie, occurring during sleep or in a sleep environment, such as a crib, bassinet, or bed) in 2004 to 2012 for 24 states (see Acknowledgments for list of states). Deaths occurring during sleep but from an explained non-sleep-related medical cause (eg, infection) or weapon-related homicide were excluded. Depending on when they began participating in the CDR-CRS, some states did not have data for all study years; however, even if a state did not provide data for all years, data from that state were still included. To ascertain factors specifically associated with deaths on sofas, we extracted and compared deidentified data from these deaths with data from other sleep-related infant deaths occurring in other locations. The institutional review board at Children's National Medical Center approved this study.

\section{Statistical Analysis}

The following variables were analyzed: infant characteristics (age, gender, race or ethnicity, complex chronic condition, or technology dependence, eg, ventilator dependence, gastrostomy tube feeds), place of incident, whether an autopsy was performed, cause of death, sleep environment factors (surface sharing, object found in sleep environment, sleep position, and sleep position change), and pregnancy characteristics (maternal medical problems, intimate partner violence, and substance use or abuse). Data elements regarding the manner and cause of death from the death certificate were used to assign cases to 1 of 3 causes of death: SIDS, accidental suffocation and strangulation in bed (ASSB, which included asphyxia), and ill-defined (which included undetermined causes). ASSB encompassed any incidents of accidental suffocation by soft bedding (including pillow or mattress), overlay, or wedging and entrapment, or strangulation in a sleep environment. 6

We performed all statistical analyses by using SPSS Statistics Data Editor version 21 (IBM Corporation, Armonk, NY), and $P$ values $<.05$ were considered statistically significant. We performed multiple imputation by using the Markov Monte Carlo method to impute missing data for variables used in the analyses. ${ }^{21,22}$ (Information on the proportions of missing data is included in Tables 1 and 2.) Multiple imputation has been previously used for analyses of the CDR-CRS database..20,23 Multiple imputation predicts values for 
TABLE 1 Study Population Characteristics

\begin{tabular}{|c|c|c|c|c|c|c|c|}
\hline \multirow[t]{2}{*}{ Characteristic } & \multicolumn{2}{|c|}{ Total } & \multicolumn{2}{|c|}{ Deaths on Sofas } & \multicolumn{2}{|c|}{$\begin{array}{l}\text { Other Sleep- } \\
\text { Related Infant } \\
\text { Deaths }\end{array}$} & \multirow[t]{2}{*}{$P$} \\
\hline & $N$ & $\%$ & $N$ & $\%$ & $N$ & $\%$ & \\
\hline Total & 7934 & 100.0 & 1024 & 100.0 & 6910 & 100.0 & \\
\hline \multicolumn{8}{|l|}{ Age (mo) } \\
\hline$<1$ & 875 & 11.0 & 137 & 13.4 & 738 & 10.7 & $<.05$ \\
\hline 1 & 1627 & 20.5 & 241 & 23.5 & 1386 & 20.1 & \\
\hline 2 & 1705 & 21.5 & 224 & 21.9 & 1481 & 21.4 & \\
\hline 3 & 1278 & 16.1 & 136 & 13.3 & 1142 & 16.5 & \\
\hline 4 & 882 & 11.1 & 104 & 10.1 & 778 & 11.3 & \\
\hline 5 & 568 & 7.2 & 61 & 5.9 & 507 & 7.3 & \\
\hline 6 & 368 & 4.6 & 37 & 3.6 & 331 & 4.8 & \\
\hline 7 & 255 & 3.2 & 34 & 3.4 & 221 & 3.2 & \\
\hline 8 & 147 & 1.9 & 20 & 2.0 & 127 & 1.8 & \\
\hline 9 & 92 & 1.2 & 13 & 1.3 & 79 & 1.1 & \\
\hline 10 & 77 & 1.0 & 9 & 0.9 & 68 & 1.0 & \\
\hline 11 & 60 & 0.8 & 7 & 0.7 & 53 & 0.8 & \\
\hline \multicolumn{8}{|l|}{ Gender } \\
\hline Male & 4622 & 58.3 & 609 & 59.5 & 4013 & 58.1 & NS \\
\hline Female & 3295 & 41.5 & 412 & 40.2 & 2883 & 41.7 & \\
\hline Unknown & 17 & 0.2 & 2 & 0.2 & 15 & 0.2 & \\
\hline Missing data & 26 & 0.3 & & & & & \\
\hline \multicolumn{8}{|l|}{ Race or ethnicity } \\
\hline Hispanic & 1536 & 19.4 & 141 & 13.8 & 1395 & 20.2 & $<.001$ \\
\hline Non-Hispanic white & 3557 & 44.8 & 502 & 49.0 & 3056 & 44.2 & \\
\hline Non-Hispanic black & 2401 & 30.3 & 335 & 32.7 & 2067 & 29.9 & \\
\hline Other race & 439 & 5.5 & 46 & 4.5 & 393 & 5.7 & \\
\hline Missing data & 302 & 3.8 & & & & & \\
\hline \multicolumn{8}{|l|}{ Place of incident } \\
\hline Child's home & 7494 & 94.5 & 986 & 96.3 & 6508 & 94.2 & $<.05$ \\
\hline Other & 265 & 3.3 & 19 & 1.8 & 247 & 3.6 & \\
\hline Unknown & 175 & 2.2 & 20 & 1.9 & 155 & 2.2 & \\
\hline Missing data & 1420 & 17.9 & & & & & \\
\hline \multicolumn{8}{|l|}{ Autopsy performed } \\
\hline Yes & 7769 & 97.9 & 996 & 97.3 & 6773 & 98.0 & NS \\
\hline No & 72 & 0.9 & 11 & 1.1 & 61 & 0.9 & \\
\hline Unknown & 93 & 1.2 & 17 & 1.7 & 76 & 1.1 & \\
\hline Missing data & 185 & 2.4 & & & & & \\
\hline \multicolumn{8}{|l|}{ Diagnosis } \\
\hline $\begin{array}{l}\text { SIDS or sudden unexpected } \\
\text { infant death }\end{array}$ & 2735 & 34.5 & 246 & 24.0 & 2489 & 36.0 & $<.001$ \\
\hline ASSB & 2139 & 27.0 & 410 & 40.0 & 1729 & 25.0 & \\
\hline III-defined & 3060 & 38.6 & 369 & 36.0 & 2691 & 38.9 & \\
\hline
\end{tabular}

NS, not significant.

incomplete variables by using regression equations from complete variables. This minimizes assumptions that the subset of cases with complete data are representative of the entire sample population. Multiple imputation is used so that biases resulting from missing data are reduced; it provides better, nearly unbiased estimates than other methods of handling missing data.21,22 All subsequent analyses were conducted with pooled imputed data. The $\chi^{2}$ test was performed for bivariate analyses to compare deaths on sofas with other sleep-related infant deaths. Multivariable, multinomial logistic regressions were performed to create adjusted odds ratios (a0Rs) of deaths on sofas compared with other sleeprelated infant deaths. Table 3 shows the aORs using imputation; Supplemental Table 4 shows the aORs for both imputed and original (unimputed) data.

\section{RESULTS}

\section{Study Population Characteristics (Table 1)}

Of the 9073 sleep-related infant deaths in the database, 7934 (87.4\%) met inclusion criteria. Of these, 1024 occurred on sofas, and 6910 occurred elsewhere. Most of the deaths on other surfaces occurred on adult beds (50.5\%), cribs (20.1\%), and bassinets (8.1\%). The majority of deaths on sofas occurred in infants age 0 to 3 months (72.1\%) and boys $(59.5 \%)$. A higher proportion of infants who died on sofas were 0 to 2 months of age (36.9\% vs $30.8 \%$ of other sleep-related deaths, $P<.05)$. NonHispanic white was the largest represented ethnicity (44.8\%) and made up a statistically significant larger proportion of the deaths on sofas than the other sleep-related deaths $(49.0 \%$ vs $44.2 \%, P<.001$ ). Most of the study population was cared for primarily by a parent (95.2\%) and did not have any complex chronic conditions (98.8\%). Most deaths (94.5\%) occurred in the infant's home, with deaths on sofas more likely than other deaths to occur in the infant's home $(96.3 \%$ vs $94.2 \%$, $P<.05$ ). Additionally, an autopsy was performed in most cases (97.9\%). The most common cause of death overall was ill-defined cause (38.6\%), followed by SIDS (34.5\%). However, the cause of death was classified as ASSB significantly more often for infants who died on sofas compared with other sleeprelated deaths $(40.0 \%$ vs $25.0 \%, P<$ .001). Overall, deaths on sofas made up $12.1 \%$ of all sleep-related deaths, $9.0 \%$ of SIDS deaths, $12.1 \%$ of ill-defined deaths, and $19.2 \%$ of ASSB deaths.

\section{Sleep Environment Factors (Table 2)}

Compared with other sleep-related infant deaths, surface sharing occurred in a significantly higher percentage ( $86.8 \%$ vs $66.2 \%, P<.001$ ), and an object was found in the sleep 
TABLE 2 Sleep Environment Factors for Deaths on Sofas and Other Sleep-Related Infant Deaths

\begin{tabular}{|c|c|c|c|c|c|c|c|}
\hline \multirow[t]{2}{*}{ Risk Factor } & \multicolumn{2}{|c|}{ Total } & \multicolumn{2}{|c|}{$\begin{array}{c}\text { Deaths on } \\
\text { Sofas }\end{array}$} & \multicolumn{2}{|c|}{ Other Deaths } & \multirow[t]{2}{*}{$P$} \\
\hline & $N$ & $\%$ & $N$ & $\%$ & $N$ & $\%$ & \\
\hline Total & 7934 & 100 & 1024 & 100.0 & 6910 & 100.0 & \\
\hline \multicolumn{8}{|l|}{ Surface sharing } \\
\hline No & 2316 & 29.2 & 111 & 10.9 & 2204 & 31.9 & \multirow[t]{4}{*}{$<.001$} \\
\hline Yes & 5466 & 68.9 & 889 & 86.9 & 4576 & 66.2 & \\
\hline Unknown & 152 & 1.9 & 23 & 2.2 & 129 & 1.9 & \\
\hline Missing data & 1864 & 23.7 & & & & & \\
\hline \multicolumn{8}{|l|}{ Object } \\
\hline Any & 2870 & 36.2 & 242 & 23.6 & 2628 & 38.0 & $<.001$ \\
\hline \multicolumn{8}{|l|}{ Position child placed to sleep } \\
\hline On back & 3232 & 40.7 & 307 & 29.9 & 2926 & 42.3 & \multirow[t]{5}{*}{$<.001$} \\
\hline On stomach & 1784 & 22.5 & 306 & 29.9 & 1478 & 21.4 & \\
\hline On side & 1032 & 13 & 134 & 13.1 & 898 & 13.0 & \\
\hline Unknown & 1885 & 23.8 & 276 & 27.0 & 1609 & 23.3 & \\
\hline Missing data & 372 & 4.7 & & & & & \\
\hline \multicolumn{8}{|l|}{ Position child found in } \\
\hline On back & 2185 & 27.5 & 205 & 20.1 & 1980 & 28.6 & \multirow[t]{4}{*}{$<.001$} \\
\hline On stomach & 3107 & 39.2 & 388 & 37.9 & 2718 & 39.3 & \\
\hline On side & 973 & 12.3 & 174 & 17.0 & 799 & 11.6 & \\
\hline Unknown & 1669 & 21 & 256 & 25.0 & 1413 & 20.4 & \\
\hline \multicolumn{8}{|l|}{ Change in child's sleep position } \\
\hline Back or side to back or side & 2658 & 33.5 & 287 & 28.1 & 2370 & 34.3 & \multirow[t]{6}{*}{$<.001$} \\
\hline Back or side to stomach & 1244 & 15.7 & 107 & 10.4 & 1137 & 16.5 & \\
\hline Stomach to stomach & 1481 & 18.7 & 230 & 22.5 & 1251 & 18.1 & \\
\hline Stomach to back or side & 156 & 2.0 & 41 & 4.0 & 115 & 1.7 & \\
\hline Either placed or found position unknown & 2395 & 30.2 & 359 & 35.0 & 2037 & 29.5 & \\
\hline Missing data & 449 & 5.7 & & & & & \\
\hline \multicolumn{8}{|l|}{ Change in sleep location } \\
\hline New or different sleep location & 1253 & 15.8 & 304 & 29.7 & 950 & 13.7 & \multirow[t]{3}{*}{$<.0001$} \\
\hline Same sleep location & 3538 & 44.6 & 132 & 12.9 & 3406 & 49.3 & \\
\hline Unknown sleep location & 3232 & 39.6 & 588 & 57.4 & 2555 & 37.0 & \\
\hline
\end{tabular}

environment significantly less frequently $(23.6 \%$ vs $38.0 \%, P<.001)$ in the deaths on sofas. Overall, infants were most commonly placed in the supine position to sleep (40.7\%), and $13 \%$ of infants in both groups were placed on the side. However, infants on sofas were more likely to be placed prone for sleep than infants in other sleep locations ( $29.9 \%$ vs $21.4 \%, P<.001$ ). Infants on sofas were also significantly more likely to be found on their side $(17.0 \%$ vs $11.6 \%, P<.001)$, whereas infants in other sleep locations were significantly more likely to be found in the supine $(28.6 \%$ vs $20.1 \%, P<.001)$ or prone $(39.3 \%$ vs $37.9 \%, P<.001)$ positions. Infants on sofas were less likely than infants in other sleep locations to change from the back or side to prone (10.4\% vs
$16.5 \%, P<.001)$ but more likely to move from prone to the back or side $(4.0 \%$ vs $1.7 \%, P<.001)$. The sofa was also more likely to be a new or different sleep location for the infant (29.7\% vs $13.7 \%, P<.0001)$.

\section{Pregnancy History}

Maternal medical problems during pregnancy and intimate partner violence during pregnancy occurred in $15.8 \%$ and $1.0 \%$ of the entire study population, respectively, with no significant difference between groups. Maternal tobacco use during pregnancy was present in $25.1 \%$ of the study population, with infants on sofas significantly more likely to have prenatal tobacco exposure than infants in other sleep locations (29.9\% vs $24.4 \%$,
$P<.001)$. Illicit drug use and heavy alcohol use during pregnancy occurred in $7.8 \%$ and $1.6 \%$ of the study population, respectively; although this proportion was slightly higher among mothers of infants who died on sofas, there were no statistically significant differences between groups. No data were available about environmental tobacco exposure or parental consumption of alcohol or illicit drugs before the last sleep.

Multivariable Analysis (Table 3 and Supplemental Table 4)

After we adjusted for all variables included in the model, deaths on sofas were less likely in Hispanic infants (aOR $0.7 ; 95 \% \mathrm{Cl}, 0.6-0.9)$ than in nonHispanic white infants. They were also more likely to be associated with surface sharing (aOR 2.4; 95\% Cl, 1.9-3.0) but less likely to be associated with objects found in the sleep environment (a0R 0.6; 95\% Cl, 0.5-0.7), compared with other sleep-related infant deaths. Infants on sofas were more likely to be placed for sleep in the prone (a0R 2.2; $95 \% \mathrm{Cl}, 1.3-3.7$ ) or side (aOR $1.4 ; 95 \% \mathrm{Cl}$, $1.0-1.8)$ positions and to be found on the side (a0R 1.9; $95 \% \mathrm{Cl}, 1.4-2.4)$. A new or different sleep location was $>6$ times more likely if the death occurred on a sofa (a0R 6.5; 95\% Cl, 5.2-8.2). Infants who died on sofas were more likely to have been exposed to tobacco in utero (a0R 1.4; $95 \% \mathrm{Cl}, 1.2-1.6$ ). The cause of death for infants who died on sofas was more likely to be classified as ASSB (OR 1.9; 95\% Cl, 1.6-2.3) or illdefined cause of death (aOR $1.2 ; 95 \% \mathrm{Cl}$, $1.0-1.5 ; P=.05)$.

\section{DISCUSSION}

It has been well documented that sleeping on a sofa is extremely hazardous for an infant and increases the risk of sudden and unexplained infant death up to 67 -fold. ${ }^{8,9,15-17}$ However, this is the first large analysis comparing 
TABLE 3 aORs (with 95\% Cl) of Sleeping on a Sofa at Time of Death (Compared With Not Sleeping on a Sofa)

\begin{tabular}{|c|c|c|c|c|}
\hline & \multirow[t]{2}{*}{$\mathrm{a} 0 \mathrm{Rs}^{\mathrm{a}}$} & \multicolumn{2}{|c|}{$95 \% \mathrm{Cl}$} & \multirow[t]{2}{*}{$P$} \\
\hline & & Lower Bound & Upper Bound & \\
\hline \multicolumn{5}{|l|}{ Age (mo) } \\
\hline $0-3 \mathrm{mo}$ & 0.93 & 0.80 & 1.1 & .4 (NS) \\
\hline 4-11 mo & Reference & & & \\
\hline \multicolumn{5}{|l|}{ Gender } \\
\hline Female & 0.9 & 0.8 & 1.1 & .4 (NS) \\
\hline Unknown & 1.2 & 0.2 & 6.1 & $.8(\mathrm{NS})$ \\
\hline Male & Reference & & & \\
\hline \multicolumn{5}{|l|}{ Race or ethnicity } \\
\hline Non-Hispanic black & 1.0 & 0.9 & 1.2 & .9 (NS) \\
\hline Hispanic & 0.7 & 0.6 & 0.9 & $<.01$ \\
\hline Other & 0.8 & 0.6 & 1.1 & .2 (NS) \\
\hline Non-Hispanic white & Reference & & & \\
\hline \multicolumn{5}{|l|}{ Location } \\
\hline Other & 0.5 & 0.2 & 1.1 & .07 (NS) \\
\hline Unknown & 0.6 & 0.1 & 4.2 & .6 (NS) \\
\hline Child's home & Reference & & & \\
\hline \multicolumn{5}{|l|}{ Surface sharing } \\
\hline Yes & 2.4 & 1.9 & 3.0 & $<.001$ \\
\hline Unknown & 2.2 & 0.9 & 5.2 & .07 (NS) \\
\hline No & Reference & Reference & Reference & \\
\hline \multicolumn{5}{|c|}{ Any object present in the sleep environment } \\
\hline Yes & 0.6 & 0.5 & 0.7 & $<.001$ \\
\hline No & Reference & & & \\
\hline \multicolumn{5}{|l|}{ Position placed for sleep } \\
\hline Prone & 2.2 & 1.3 & 3.7 & $<.01$ \\
\hline Side & 1.4 & 1.0 & 1.8 & $<.05$ \\
\hline Unknown & 1.0 & 0.7 & 1.4 & .9 (NS) \\
\hline Supine & Reference & & & \\
\hline \multicolumn{5}{|l|}{ Position change } \\
\hline Supine/side to prone & 0.9 & 0.5 & 1.5 & .6 (NS) \\
\hline Prone to prone & 0.8 & 0.4 & 1.7 & .6 (NS) \\
\hline Prone to supine or side & 0.9 & 0.4 & 1.8 & .8 (NS) \\
\hline Unknown & 1.0 & 0.6 & 1.6 & .9 (NS) \\
\hline Supine or side to supine or side & Reference & & & \\
\hline \multicolumn{5}{|l|}{ Position found } \\
\hline Prone & 1.4 & 0.8 & 2.4 & .3 (NS) \\
\hline Side & 1.9 & 1.4 & 2.4 & $<.001$ \\
\hline Unknown & 1.3 & 0.8 & 1.9 & .3 (NS) \\
\hline Supine & & & & \\
\hline \multicolumn{5}{|l|}{ Change in sleep location } \\
\hline Different location & 6.5 & 5.2 & 8.1 & $<.001$ \\
\hline Unknown & 5.1 & 4.1 & 6.2 & $<.001$ \\
\hline Same location & Reference & & & \\
\hline \multicolumn{5}{|l|}{ Maternal smoking during pregnancy } \\
\hline Yes & 1.4 & 1.2 & 1.6 & $<.001$ \\
\hline No & Reference & & & \\
\hline \multicolumn{5}{|l|}{ Diagnosis of cause of death } \\
\hline III-defined & 1.2 & 1.0 & 1.5 & $<.05$ \\
\hline ASSB & 1.9 & 1.6 & 2.3 & $<.001$ \\
\hline SIDS & Reference & & & \\
\hline
\end{tabular}

NS, not significant.

a Adjusted for all variables in the model.

factors associated with infant deaths on sofas with factors associated with other sleep-related infant deaths. This analysis demonstrates that deaths on sofas make up a large proportion of sleep-related infant deaths. Furthermore, these deaths are significantly more likely, compared with other sleep-related infant deaths, to be associated with surface sharing, nonsupine placement, being found in the side position, a change in usual sleep location, and in utero tobacco exposure.

The finding of a greater association between sleeping on a sofa and surface sharing may be due in part to the inherent use of this type of furniture. Sofas and similar objects are often shared with others and are meant to be used during waking hours. Sharing a sofa with an infant is becoming increasingly common in some countries ${ }^{24}$ and may be done to calm or feed the infant, and the parent may inadvertently or intentionally fall asleep with the infant. 24,25

It has been assumed that much of the risk associated with sleeping on a sofa results from the soft cushioning and sloping surface of sofas. The American Academy of Pediatrics specifically recommends that infants sleep on a firm, flat surface and that soft cushions and pillows be avoided. ${ }^{12}$ The soft surface of most sofas may create rebreathing and a potentially asphyxiating environment for infants, especially if they are placed in a nonsupine position. ${ }^{26}$ Some sofa surfaces also slope down toward the back cushions, which makes it easier for infants to roll and wedge between the seat and back-supporting surface. In this sample, infants who died on sofas were more likely than those who died on other surfaces to be found in the side position. Sleeping on the side with one's face against the back cushions of the sofa or against another person can result in suffocation. ${ }^{27}$ Past analyses have found that infant deaths on sofas are usually asphyxia deaths from entrapment between a person and the sofa cushions, overlay by another person, or wedging against the sofa cushions. ${ }^{18,28,29}$ Indeed, the cause of death for infants on sofas in this sample was most frequently classified as ASSB rather than SIDS. 
Infants in the sofa group were more likely to be placed in a nonsupine position. The prone and side sleeping positions increase the risk of sudden and unexplained infant death during any sleep, including napping. ${ }^{30}$ However, caregivers may be less aware or less concerned about the infant's sleeping position if they believe that they will be awake and observing the infant. ${ }^{31}$ Anecdotal data suggest that parents often place their infants on sofas when they will be in the same room and want the infant within sight (R.Y.M., unpublished data). Indeed, a high priority for many parents is to ensure that they can closely monitor their infant, whether the parent is awake or asleep, ${ }^{31,32}$ and this is thought to be best done when the infant is within sight and hearing distance. This may also explain why, when infant deaths occurred on sofas, the sofa was likely to be a new or different sleep location, that is, not the usual location for the infant to sleep. Surveys of sleep location have not found sofas to be a commonly used sleep location for infants. ${ }^{32,33}$ Although we do not have data about time of death, it is possible that many of these infants were placed on a sofa, when this was not a usual sleep location, for naps while the parent was in the same room, or on the parent's chest while the parent was lying down on the sofa. However, it should be noted that a change in sleep environment may be associated with an increased risk of death. ${ }^{34}$

Maternal tobacco use during pregnancy has been demonstrated to be a major risk factor for SIDS, ${ }^{35-38}$ increasing the risk of SIDS twofold. ${ }^{39}$ It is unclear why infants who die on sofas are more likely to have mothers who smoke. However, this is consistent with Ball and colleagues' 40 findings that sleeping with an infant on a sofa was $79 \%$ more likely if the mother was a smoker. It may be that those who place infants in an unsafe sleep environment are also less informed about other SIDS risk factors, such as prenatal maternal tobacco use. Smoking is also more common among low-income women, ${ }^{41}$ and lower-income families are, in general, at higher risk of sleeprelated infant deaths. ${ }^{3}$

This study has several limitations. Despite being a large database, the CDRCRS does not include child deaths from all states or all child deaths within a state, because participation in the case reporting system is voluntary and not all child deaths are reviewed. ${ }^{19}$ Thus, the CDR-CRS is not a comprehensive population-based database, nor does it contain comparison data for nonaffected infants. As a result, it is impossible to determine an appropriate denominator for the deaths included in the study. ${ }^{20}$ Second, despite its definitions of variables and a standardized reporting system, the quality of the data varies between states because of differences in reporters and failure to routinely access the data dictionary. In addition, some variables have large proportions of missing data, which was found to be more likely with novice reporters and decreased with time. ${ }^{19}$ Consequently, data were imputed to account for missing values. It should also be noted that these deaths included all sleep-related infant deaths, including those for which the sleep surface was unknown. Other studies that have examined deaths on sofas have been epidemiologic ana-

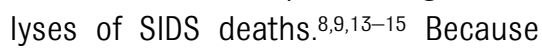
there has recently been a shift in how the cause of death is coded for sudden and unexpected infant deaths in the United States, ${ }^{7}$ we chose to examine all deaths occurring suddenly and unexpectedly. Nonetheless, we acknowledge that this encompasses deaths from causes that are both explained (eg, accidental suffocation) and unexplained (ill-defined and SIDS). This implies that there may be $>1$ mechanism of death on sofas. Finally, the information available about the final sleep of these infants is limited compared with observational case-control studies and does not include socioeconomic status or specific circumstances, such as who was on the sofa with the infant, whether they were sleeping, whether they intended to sleep with the infant, and whether any alcohol or sleep-inducing drugs were consumed before the death.

Despite its limitations, the CDR-CRS has numerous strengths. The database captures a wealth of critical information on child deaths and houses it in 1 location. ${ }^{19}$ Additionally, the CDR-CRS is continually growing as new states begin to participate in the review process, ${ }^{19}$ thereby expanding the data available for analysis. The expanding database and improvement in data quality will enable the CDRCRS to broaden its ability to identify risk factors and elucidate the circumstances surrounding all types of child deaths.

\section{CONCLUSIONS}

Infant deaths occurring on sofas make up a large proportion of sleep-related infant deaths. They are more likely to be associated with nonsupine placement for sleep, being found in the side position, surface sharing, changes in sleep environment, and in utero tobacco exposure, compared with other sleep-related infant deaths in the CDRCRS database. These results may help explain why sofa sleeping is hazardous for infants. Although it is unclear why deaths on sofas are associated with these factors, these data indicate that many parents and caregivers may consider the sofa to be a safe environment in which the infant can sleep while remaining within sight and hearing range. Given that the risk of death for infants sleeping on sofas is so 
high, it is important that parents and caregivers be educated about safe sleep guidelines in general and, more specifically, the dangers of placing infants for sleep on sofas and similar surfaces and sharing these surfaces with an infant.

\section{ACKNOWLEDGMENTS}

This data set was provided by the National Center for the Review and

\section{REFERENCES}

1. MacDorman MF, Hoyert DL, Mathews TJ. Recent declines in infant mortality in the United States, 2005-2011. NCHS data brief. Atlanta, GA: Centers for Disease Control and Prevention; 2013

2. US Department of Health and Human Services. Centers for Disease Control and Prevention (CDC), National Center for Health Statistics (NCHS), Office of Analysis and Epidemiology (OAE), Division of Vital Statistics (DVS), Linked Birth / Infant Death Records on CDC WONDER Online Database. Available at: http://wonder.cdc.gov/lbd.html

3. Moon RY; Task Force on Sudden Infant Death Syndrome. Technical Report: SIDS and other sleep-related infant deaths: expansion of recommendations for a safe infant sleeping environment. Pediatrics. 2011;128(5). Available at: www.pediatrics. org/cgi/content/full/128/5/e1341

4. Kattwinkel J, Brooks J, Myerberg D. American Academy of Pediatrics AAP Task Force on Infant Positioning and SIDS: positioning and SIDS. [Erratum in: Pediatrics 1992 Aug; 90(2 Pt 1): 264] Pediatrics. 1992;89(6 pt 1):1120-1126

5. Malloy MH, MacDorman M. Changes in the classification of sudden unexpected infant deaths: United States, 1992-2001. Pediatrics. 2005;115(5):1247-1253

6. Shapiro-Mendoza CK, Kimball M, Tomashek KM, Anderson RN, Blanding S. US infant mortality trends attributable to accidental suffocation and strangulation in bed from 1984 through 2004: are rates increasing? Pediatrics. 2009;123(2):533-539

7. Shapiro-Mendoza CK, Tomashek KM, Anderson RN, Wingo J. Recent national trends in sudden, unexpected infant deaths: more evidence supporting a change in classification or reporting. Am J Epidemiol. 2006;163 (8):762-769

8. Hauck FR, Herman SM, Donovan M, et al. Sleep environment and the risk of sudden
Prevention of Child Deaths, which is funded in part by grant U49MC00225 from the US Department of Health and Human Services, Health Resources and Services Administration, and in part by the US Centers for Disease Control and Prevention Division of Reproductive Health. The contents are solely the responsibility of the authors and do not necessarily represent the official views of the National Center

infant death syndrome in an urban population: the Chicago Infant Mortality Study. Pediatrics. 2003;111(5 pt 2):1207-1214

9. Tappin D, Ecob R, Brooke H. Bedsharing, roomsharing, and sudden infant death syndrome in Scotland: a case-control study. J Pediatr. 2005;147(1):32-37

10. Vennemann MM, Hense HW, Bajanowski T, et al Bed sharing and the risk of sudden infant death syndrome: can we resolve the debate? J Pediatr. 2012;160(1):44-48.e2

11. Thach BT, Rutherford GW Jr, Harris K. Deaths and injuries attributed to infant crib bumper pads. J Pediatr. 2007;151(3): 271-274, e1-e3

12. Moon RY; Task Force on Sudden Infant Death Syndrome. Policy Statement: SIDS and other sleep-related infant deaths: expansion of recommendations for a safe infant sleeping environment. Pediatrics. 2011;128(5):1030-1039

13. Colson ER, Rybin D, Smith LA, Colton T, Lister G, Corwin MJ. Trends and factors associated with infant sleeping position: the National Infant Sleep Position Study, 1993-2007. Arch Pediatr Adolesc Med. 2009; 163(12):1122-1128

14. Colson ER, Willinger $M$, Rybin $D$, et al. Trends and factors associated with infant bed sharing, 1993-2010: the National Infant Sleep Position Study. JAMA Pediatr. 2013; 167(11):1032-1037

15. Blair PS, Fleming PJ, Smith IJ, et al. Babies sleeping with parents: case-control study of factors influencing the risk of the sudden infant death syndrome. CESDI SUDI research group. BMJ. 1999;319(7223):14571461

16. Fleming PJ, Blair PS, Bacon C, et al; Confidential Enquiry Into Stillbirths and Deaths Regional Coordinators and Researchers. Environment of infants during sleep and risk of the sudden infant death syndrome: for the Review and Prevention of Child Deaths, the US Department of Health and Human Services, or the participating states. Twenty-four states contributed data, including Alabama, Arizona, California, Colorado, Connecticut, Delaware, Georgia, Hawaii, lowa, Michigan, Minnesota, Nebraska, Nevada, New Jersey, Ohio, Oklahoma, Rhode Island, Tennessee, Texas, West Virginia, and Wisconsin. results of 1993-5 case-control study for confidential inquiry into stillbirths and deaths in infancy. BMJ. 1996;313(7051): 191-195

17. McGarvey C, McDonnell M, Chong A, O'Regan $M$, Matthews T. Factors relating to the infant's last sleep environment in sudden infant death syndrome in the Republic of Ireland. Arch Dis Child. 2003;88(12):1058-1064

18. Byard RW, Beal S, Blackbourne B, Nadeau JM, Krous HF. Specific dangers associated with infants sleeping on sofas. J Paediatr Child Health. 2001;37(5):476-478

19. Covington TM. The US National Child Death review case reporting system. Inj Prev. 2011;17 (suppl 1):i34-i37

20. Schnitzer PG, Covington TM, Dykstra HK. Sudden unexpected infant deaths: sleep environment and circumstances. Am J Public Health. 2012;102(6):1204-1212

21. Baraldi AN, Enders CK. An introduction to modern missing data analyses. J Sch Psychol. 2010;48(1):5-37

22. Howell DC. The treatment of missing data. In: Outhwaite W, Turner S, eds. SAGE Handbook of Social Science Methodology. London, UK: SAGE; 2008:1-44

23. Colvin JD, Collie-Akers V, Schunn C, Moon RY. Sleep environment risks for younger and older infants. Pediatrics. 2014;134(2). Available at: www.pediatrics.org/cgi/content/full/134/2/e406

24. Blair PS, Sidebotham P, Evason-Coombe C, Edmonds M, Heckstall-Smith EM, Fleming P. Hazardous cosleeping environments and risk factors amenable to change: casecontrol study of SIDS in south west England. BMJ. 2009;339:b3666

25. Kendall-Tackett K, Cong Z, Hale TW. Motherinfant sleep locations and nighttime feeding behavior: U.S. data from the Survey of Mothers' Sleep and Fatigue. Clin Lactation 2010;1:27-31 
26. Kemp JS, Livne M, White DK, Arfken CL. Softness and potential to cause rebreathing: differences in bedding used by infants at high and low risk for sudden infant death syndrome. J Pediatr. 1998;132(2): 234-239

27. Pasquale-Styles MA, Tackitt PL, Schmidt CJ. Infant death scene investigation and the assessment of potential risk factors for asphyxia: a review of 209 sudden unexpected infant deaths. I Forensic Sci. 2007;52(4):924-929

28. Li L, Zhang Y, Zielke RH, Ping Y, Fowler DR. Observations on increased accidental asphyxia deaths in infancy while cosleeping in the state of Maryland. Am J Forensic Med Pathol. 2009;30(4):318-321

29. Scheers NJ, Rutherford GW, Kemp JS. Where should infants sleep? A comparison of risk for suffocation of infants sleeping in cribs, adult beds, and other sleeping locations. Pediatrics. 2003;112(4):883-889

30. Hauck FR, Moore CM, Herman SM, et al. The contribution of prone sleeping position to the racial disparity in sudden infant death syndrome: the Chicago Infant Mortality Study. Pediatrics. 2002;110(4):772-780
31. Moon RY, Oden RP, Joyner BL, Ajao TI. Qualitative analysis of beliefs and perceptions about sudden infant death syndrome (SIDS) among African-American mothers: implications for safe sleep recommendations. J Pediatr. 2010;157:92-7.e2.

32. Joyner BL, Oden RP, Ajao TI, Moon RY. Where should my baby sleep: a qualitative study of African American infant sleep location decisions. J Natl Med Assoc. 2010;102(10): 881-889

33. Fu LY, Colson ER, Corwin MJ, Moon RY. Infant sleep location: associated maternal and infant characteristics with sudden infant death syndrome prevention recommendations. J Pediatr. 2008;153(4):503-508

34. Moon RY, Patel KM, Shaefer SJ. Sudden infant death syndrome in child care settings. Pediatrics. 2000;106(2 Pt 1):295-300

35. Schoendorf KC, Kiely JL. Relationship of sudden infant death syndrome to maternal smoking during and after pregnancy. $P e-$ diatrics. 1992;90(6):905-908

36. Markowitz S. The effectiveness of cigarette regulations in reducing cases of sudden infant death syndrome. J Health Econ. 2008; 27(1):106-133
37. Tong VT, Jones JR, Dietz PM, D'Angelo D, Bombard JM; Centers for Disease Control and Prevention (CDC). Trends in smoking before, during, and after pregnancy: Pregnancy Risk Assessment Monitoring System (PRAMS), United States, 31 sites, 2000-2005. MMWR Surveill Summ. 2009;58 (4): $1-29$

38. MacDorman MF, Cnattingius S, Hoffman HJ, Kramer MS, Hagllund B. Sudden infant death syndrome and smoking in the United States and Sweden. Am J Epidemiol. 1997; 146(3):249-257

39. Anderson ME, Johnson DC, Batal HA. Sudden infant death syndrome and prenatal maternal smoking: rising attributed risk in the Back to Sleep era. $B M C$ Med. 2005;3:4

40. Ball HL, Moya E, Fairley L, Westman J, Oddie S, Wright J. Bed- and sofa-sharing practices in a UK biethnic population. Pediatrics. 2012;129(3):e673-e681

41. Centers for Disease Control and Prevention (CDC). Cigarette smoking among adults and trends in smoking cessation: United States, 2008. MMWR Morb Mortal Wkly Rep. 2009; 58(44):1227-1232 